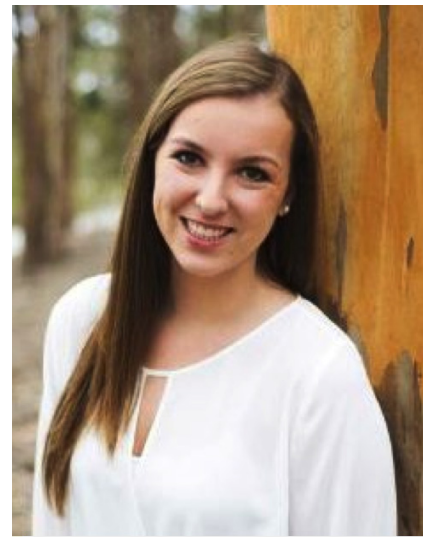

KRISTEN HENRY is a fourth year Business Administration major with a minor in Political Science. She began writing this paper while taking the course Critical Issues in American Politics. The more she learned about the Common Core standards, the more interested she became in assessing its true value. After she graduates, Kristen will be moving to Austin, Texas, to be a consultant for a software company. 


\section{AN EXAMINATION OF THE DEBATE SURROUNDING CORE CURRICULUM STATE STANDARDS IN AMERICAN EDUCATION REFORM}

Kristen Henry

\section{Core Curriculum State Standards in American Education Reform}

The creation and implementation of the Common Core State Standards (CCSS) has been a heated topic of debate in American politics, garnering attention from teachers, school administrators, and parents across the country. Many states have adopted these guidelines, which are a set of learning objectives for students at each grade level in Mathematics and English-language arts. ${ }^{1}$ Since its original implementation, however, support for CCSS has been wavering, with criticism coming from both Republicans and Democrats. ${ }^{2}$ Many supporters of Common Core State Standards argue that implementation will create a uniform level of comparison between states and ensure that

\footnotetext{
${ }^{1}$ Williams, Cheryl S. "Just the Facts: Common Core State Standards." Educational Horizons 90.4 (2012): 8-9.

${ }^{2}$ Guillory, John. "The Common Core And The Evasion Of Curriculum." PMLA: Publications Of The Modern Language Association Of America 30.3 (2015): 666-672.
} 
the nation adequately prepares students for life beyond high school, while critics address the program's associated costs and inability to target the real issues behind education inequality. Whether or not this program is the best path for America's education system moving forward is still up for debate.

The Common Core Standards themselves were designed by the National Governors Association for Best Practices (NGA) and Council of Chief State School Officers (CCSSO), and are aimed to "prepare students for college, career, and beyond." ${ }^{3}$ In addition to the NGA and the CCSSO, private groups were involved in the development as well. ${ }^{4}$ The most notable contribution came from the Bill and Melinda Gates Foundation, a large and powerful philanthropy group. ${ }^{5}$ Additional support and funding came from many educational interests including ACT, Microsoft, The College Board, McGrawHill Education, and Pearson Education. ${ }^{6}$ The standards were developed with contributions from these private groups whose relevant interests may impede on their ability to make impartial policy choices. In 2009 the Department of Education announced a fund called the Race to the Top, which encouraged "states to compete for $\$ 4.35$ billion by earning points based on education reform plans," which they would have the chance to adopt. ${ }^{7}$ The program made it clear that to be competitive, a state must include "internationally benchmarked standards and assessments that prepare students for success in the workforce and college," ${ }^{8}$ which was another way of saying they must adopt CCSS and its respective assessments. ${ }^{9}$ In 2010, forty-six states applied, twelve of which received federal funding. ${ }^{10}$ As of Fall 2014, four states had

\footnotetext{
${ }^{3}$ Burks, Brooke. "Adapting To Change: Teacher Perceptions Of Implementing The Common Core State Standards." Education 136.2 (2015): 253-258.

${ }^{4}$ Crowder, Zan. "From The Editorial Board: The Politicization Of The Common Core." High School Journal 98.1 (2014): 1-4.

5 Ibid.

${ }^{6}$ Ibid.

7 Frye, Kristopher. "Can The Common Core Counter Educational Inequity? International Legal Lessons On Closing The Achievement Gap." Indiana International \& Comparative Law Review 25.3 (2015): 493-540.

8 Toscano, Michael. “The Common Core: Far From Home.” Academic Questions 26.4 (2013): 411-428.

9 Op. Cit., fn. 7

${ }^{10}$ Op. Cit., fn. 8
} 
withdrawn from their commitment due in part to the high costs associated. ${ }^{11}$ As the program develops, states are continuing conversations about its effectiveness for educational reform.

Supporters of the Common Core State Standards maintain that implementation will create a consistent level of comparison between states and effectively prepare students for an international job market. A uniform set of standards "would address the problem of curriculum variation in the United States." 12 This consistency between state education systems would "promote educational equity" and allow for accurate comparative assessments between states. ${ }^{13}$ The wide variability that exists within a less centralized system of state-generated guidelines makes such a comparison nearly impossible. A common core system would also be especially beneficial to families who move between states by reducing repetition or gaps in their K-12 education. Another area that is often cited in support of CCSS is one of the program's main objectives: to "prepare students to compete in the ever-changing job market and the global economy." 14 According to a 2013 study conducted by the US Department of Education, 20\% of college freshmen reported that they had been enrolled in a remedial course during their first year in higher education. ${ }^{15}$ Burks argues that CCSS will reduce the need for these course offerings at colleges and universities, and better prepare students for college-level coursework. ${ }^{16}$ Supporters of CCSS reason that these standards will raise levels of expectation and transparency throughout American education, and will also provide students with "a certain set of educational skills one must have to be successful in academia or business." ${ }^{17}$ This central skill set is crucially important for students everywhere, and the uniform tests would allow policymakers to make accurate comparisons between states.

Critics of CCSS argue that the federal government is reaching too far with the program, that it does not adequately address the real issues within

\footnotetext{
${ }^{11}$ Op. Cit., fn. 4

${ }^{12}$ Op. Cit., fn. 3

13 Op. Cit., fn. 7

${ }^{14}$ Op. Cit., fn. 3

15 Op. Cit., fn. 3

${ }^{16}$ Op. Cit., fn. 3

${ }^{17}$ Op. Cit., fn. 7
} 
education, and that the associated costs are too high. Toscano writes that the biggest flaw of state standards is due to their disordered relation to social spheres and the "full reordering of American education away from families and local communities." ${ }^{18}$ He argues that the actions of the federal government were unilateral, merely concealed as being in the interest of the states, and primarily focuses on the overpowering involvement of the Bill and Melinda Gates Foundation. ${ }^{19}$ He argues that their "aggressive spending power" and incentive structure made it difficult for states to turn down the chance to seek funding. ${ }^{20}$ Although the decision to adopt CCSS was noncompulsory, states with struggling education budgets would be hard-pressed to turn down such an opportunity. Whether or not the path to common core was the most democratic, there are still criticisms regarding other aspects of the program, particularly how CCSS addresses the effect of poverty.

Supporters claim that CCSS is necessary to compete internationally, and they often cite America's comparatively poor performance on standardized assessments. Upon closer inspection, research indicates that "analyses of our international test scores ... are nowhere nearly as bad as critics claim and that they have not declined." ${ }^{21}$ Scholars like Stephen Krashen of the University of Southern California have found through "longitudinal international studies...that low test scores are largely clustered in the poorest school districts, while middle-class American students in well-funded schools score at the top of the world on international tests." 22 This is a crucial discrepancy to acknowledge, especially since poverty levels play a big part in education both through both student distribution and state funding. A study conducted at the College of William \& Mary found that "economic segregation in public schools is higher than expected [when compared to] the distribution of poverty across neighborhoods." 23 This is especially concerning because the

\footnotetext{
${ }^{18}$ Op. Cit., fn. 8

19 Ibid.

${ }^{20}$ Ibid.

${ }^{21}$ Krashen, Stephen. “The Common Core.” Knowledge Quest, 2014: 36-45.

${ }^{22}$ Wexler, Alice. "Reaching Higher? The Impact Of The Common Core State Standards

On The Visual Arts, Poverty, And Disabilities." Arts Education Policy Review 115.2 (2014): 52-61.

23 Saporito, and Sohoni. "Mapping Educational Inequality." Social Forces 85, no. 3 (2007).
} 
same study indicated a "strong correlation between school-level poverty rates and the academic achievement of individual students. ${ }^{24}$ Implementing a common set of guidelines across the nation overlooks the effect of poverty levels on educational achievement, primarily when they exist within the states themselves. The overbearing focus on CCSS over more serious issues detracts resources from significant programs like food security, healthcare, and access to books, that impact school performance. ${ }^{25}$

The additional costs associated with CCSS are another area of concern. The new assessments require computer hardware and software, and a new set of learning objectives requires new textbooks. ${ }^{26}$ This is especially concerning for students in high poverty schools since "the size of the gaps in achievement among schools and districts suggests that the additional costs will be high." ${ }^{27}$ Many districts struggle with budgets and providing attractive teaching salaries, resulting in less experienced teachers who serve high proportions of minority students and students living in poverty. ${ }^{28}$ The addition of more costs and required resources would put an even larger strain on communities with fewer instructional resources to begin with, and may perpetuate the educational gap the program aims to remedy.

After examining the Common Core Standards laid out by the federal government, it is hard to disagree with the objectives. Preparing students for college and the workforce, staying competitive among other nations, and creating an education system that can be benchmarked are all respectable goals. The biggest issue within CCSS, however, is not the stated guidelines, but the oversimplification of underlying problems that the standards claim to improve. Toscano states that the "Common Core... is a product of major misdiagnosis of what ails American schooling" 29 and that "[e]ducational success... is dependent upon the child's ability to participate in healthy families and

24 Ibid.

25 Op. Cit., fn. 21

26 Ibid.

${ }^{27}$ McPartland, James M, and Barbara Schneider. "Opportunities To Learn And Student Diversity: Prospects And Pitfalls Of A Common Core Curriculum.” 1996: 66-81.

${ }^{28}$ Hammond, Adamson, and Darling Hammond. "Funding disparities and the inequitable distribution of teachers: Evaluating sources and solutions." Education Policy Analysis Archives 20 (2012).

29 Op. Cit., fn. 8 
communities." ${ }^{30}$ This distinction puts children in poverty, and by extension a high population of minority children back at the starting line, or possibly worse. CCSS has a heavy emphasis on assessment to track the development of the program, and Wexler points to research that says "the social effects of poverty... are factors that contribute to learning....and, inevitably, low performance on standardized tests." ${ }^{31}$ This speaks to the greater problem that CCSS fails to address, which "is the child outside of school." ${ }^{22}$ Children with unstable living situations, estranged families, or who do not receive their proper meals are not able to concentrate at the level necessary to succeed in the classroom. One other overarching issue that makes the argument for CCSS even less compelling is the process by which the standards came about. Criticism has arisen from many experts, including James Milgram, professor emeritus of mathematics at Stanford. Milgram was a member of the Common Core Validation Committee, and refused to sign off on the standards. He noted the high risks associated with implementation, and claimed "[with the CCSS] we are dealing with an experiment on a national scale." ${ }^{33}$ Others have called for the public to "demand that experiments and descriptive studies of groups of students be carried out so that the standards and measure can be evaluated." ${ }^{34}$ This argument is especially critical since one of the overarching goals of CCSS is to increase educational equity. ${ }^{35}$

At this point, more research is necessary to evaluate whether or not the Common Core State Standards will have the positive effect they are intended to. The goals themselves are respectable, however the program must take on a more holistic view of underlying issues such as poverty and funding discrepancies. Policymakers and researchers should utilize their resources to conduct testing on a smaller scale before implementing the program nationwide. It is not clear whether or not CCSS is the best solution for America, but supporters and critics can both agree that effective and lasting educational reform is long overdue.

\footnotetext{
30 Ibid.

31 Op. Cit., fn. 22

32 Op. Cit., fn. 22

33 Op. Cit., fn. 8

34 Op. Cit., fn. 21

35 Op. Cit., fn. 1
} 